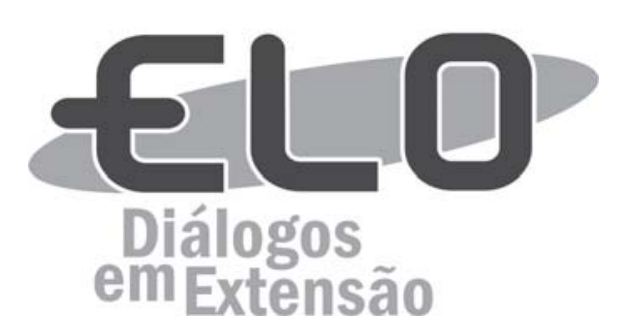

\title{
Extensão universitária e biodiversidade: promovendo educação ambiental nas Encostas da Serra Geral - sul de Santa Catarina
}

\author{
Ismael Dagostin-Gomes ${ }^{1}$, Luciano Giassi ${ }^{2}$, Ana Sônia Mattos ${ }^{3}$, Anderson \\ Volpato Alves ${ }^{4}$, Rosivete Coan Niehues ${ }^{5}$, Antonio Formigoni de Luca
}

\begin{abstract}
Resumo: A extensão universitária e a educação ambiental são dois importantes eixos de atuação do Centro Universitário Barriga Verde - Unibave, Orleans - sul de Santa Catarina. Dessa forma, este trabalho tem o objetivo de relatar o projeto de extensão "Biodiversidade e Educação Ambiental" desenvolvido pelo curso de Engenharia Ambiental e Sanitária do Unibave, em escolas de Ensino Médio das Encostas da Serra Geral, região do Campus Orleans. Trata-se de uma série de exposições organizadas em cada unidade escolar, composta por animais taxidermizados representantes da Mata Atlântica, além de informações ecológicas e de relação antrópica com essa fauna. Entre setembro e dezembro de 2016, o projeto de extensão oportunizou conhecimento biológico e sensibilização ambiental para 2.758 alunos do Ensino Médio (5.397 quando considerados, também, os dos Anos Finais do Ensino Fundamental), em 11 escolas de 07 municípios, contribuindo para o desenvolvimento regional sustentável.
\end{abstract}

Palavras-chave: Educação ambiental. Extensão universitária. Biodiversidade.

Área Temática: Educação; Meio Ambiente.

\section{University extension and biodiversity: promoting environmental education in Encostas da Serra Geral, south of Santa Catarina}

Abstract: University extension and environmental education are two important areas of action of Centro Universitário Barriga Verde - Unibave, Orleans, south of Santa Catarina. As such, this work has the objective to report the extension project "Biodiversity and Environmental Education" developed by Unibave's Sanitary and Environmental Engineering course in the high schools in Encostas da Serra Geral, the region around Orleans Campus. A series of exhibitions were organized in each school unit. They were composed by taxidermied animals representing the Atlantic Forest, the ecological information and its anthropic relation with is fauna. Between september and december of 2016, the extension project provided biology knowledge and environmental sensitization for 2.758 High School students (5.397 if considering the students from Middle School), in 11 schools from siete cities, contributing for the sustainable development in the region.

Keywords: Environmental education. University extension. Biodiversity.

\footnotetext{
${ }^{1}$ Doutorando em Ciência e Tecnologia Ambiental, Me. em Biologia, Licenciado em Ciências Biológicas e Engenheiro Agrônomo. Coordenador do Curso de Eng. Ambiental e Sanitária do Centro Universitário Barriga Verde - UNIBAVE (Orleans - SC) e Professor da Escola Educacional Técnica - SATC (Criciúma - SC). Rua Pe. João Leonir Dall'Alba, 601, Bairro Murialdo, Orleans - SC. Tel: (48) 34665600 ou 34317500. E-mail: ismaeldagostin@yahoo.com.br.

${ }^{2}$ Me. em Eng. de Materiais, Graduado em Química. Docente do UNIBAVE.

${ }^{3}$ Ma. em Ciência e Eng. de Mat., Graduada em Química. Docente do UNIBAVE.

${ }^{4}$ Me. em Educação, Graduado em Ciências: Matemática. Docente do UNIBAVE.

${ }^{5}$ Ma. em Engenharia Elétrica, Graduada em Física. Docente do UNIBAVE.

${ }^{6}$ Esp. em Didática no Ensino Sup., Eng. San. e Amb. Docente do UNIBAVE.
} 


\section{Extensión universitaria y la biodiversidad: promoción de la educación ambiental en la Región de la Sierra General, sur de Santa Catarina}

Resumen: La extensión universitaria y la educación ambiental son dos ejes importantes de actuación del Centro Universitario Barriga Verde - Unibave, Orleans, sur de Santa Catarina. Por lo tanto, este estudio tiene como objetivo informar sobre el proyecto de extensión "Biodiversidad y Educación Ambiental" desarrollado por el curso de Ingeniería Ambiental y Sanitaria de Unibave en escuelas de Educación Secundaria de la Región de la Sierra General, área del Campus Orleans. Se trata de una serie de exposiciones organizadas en cada unidad escolar, que consiste en animales taxidermizados representantes del Bosque Atlántico, información ecológica y de relación antrópico con esta fauna. Entre septiembre y diciembre de 2016, el proyecto de extensión proporcionó una oportunidad de conocimiento biológico y la conciencia ambiental a 2.758 estudiantes de la Secundaria (5.397 cuando, también, se considera los Años Finales de la Educación Primaria) en 11 escuelas y en siete municipios, contribuyendo al desarrollo sostenible de la región.

Palabras clave: Educación ambiental. Extensión universitaria. Biodiversidad.

\section{Introdução}

A extensão universitária, elo entre a universidade e a comunidade, é um dos elementos mais presentes dentre as atividades desenvolvidas pelo Centro Universitário Barriga Verde - Unibave, cujo Campus é sediado no município de Orleans, sul de Santa Catarina. Tal panorama pode ser visualizado nas próprias diretrizes institucionais, que oportunizam uma educação criativa, sistêmica e sustentável, contribuindo com o desenvolvimento regional (UNIBAVE, 2014).

Alinhado com essas premissas, o Unibave tem se destacado em ações relacionadas ao meio ambiente e ao saneamento;; uma destsas ações foi realizada pelo curso de Engenharia Ambiental e Sanitária envolvendo acadêmicos, coordenação e colaboradores da instituição.

Trata-se do projeto de extensão "Biodiversidade e Educação Ambiental”, desenvolvido em escolas de Ensino Médio da região do Campus Orleans, compreendida como região das Encostas da Serra Geral.

Nesta perspectiva, concordando com Pedrini (1997, p. 32), que defende que "o que causa a degradação ambiental é, dentre outros motivos, a falta de educação ambiental", percebe-se o desconhecimento, por parte dos alunos, sobre a biodiversidade local (fauna e flora, por exemplo) - e a desconexão com questões sociais, econômicas, políticas e culturais - podem comprometer a qualidade ambiental da região para as próximas gerações.

Assim,

todas as recomendações, decisões e tratados internacionais sobre o tema evidenciam a importância atribuída por lideranças de todo o mundo para a Educação Ambiental como meio indispensável para conseguir criar e aplicar formas cada vez mais sustentáveis de interação sociedade/natureza e soluções para os problemas ambientais. Evidentemente, a educação sozinha não é suficiente para mudar os rumos do planeta, mas certamente é condição necessária para isso. (BRASIL, 1997, p. 15).

Deste modo, este trabalho tem o propósito de relatar uma experiência de extensão universitária desenvolvida pelo curso de Engenharia Ambiental e Sanitária do Unibave em escolas da região do Campus Orleans, sul de Santa Catarina.

\section{Metodologia}

O projeto foi mediado por meio do envolvimento de acadêmicos e coordenação do Curso de Engenharia Ambiental e Sanitária do Unibave, além de colaboradores da instituição, entre setembro e dezembro de 2016.

O objetivo principal do projeto era disseminar informações biológicas e suscitar a sensibilização ambiental em instituições de ensino, públicas ou privadas, que possuíssem o Ensino Médio. Como objetivos específicos, destacam-se: estreitar o relacionamento entre o Unibave e as escolas; elevar a 
exposição do curso de Engenharia Ambiental e Sanitária; sedimentar o projeto de extensão do curso de Engenharia Ambiental e Sanitária; atuar como uma política de educação ambiental e sustentabilidade (como exigido nos instrumentos de avaliação); desenvolver uma engenharia preventiva para questões ambientais.

A iniciativa para agendar a exposição pôde ser realizada via telefone pela Equipe de Marketing, que possuía o contato e o relacionamento com as escolas, ou por intermédio de convite direto realizado pelas escolas, geralmente via e-mail.

Com o agendamento estabelecido, o transporte do material didático-pedagógico da exposição era realizado por automóvel institucional, sem custo para as unidades escolares.

Nas escolas, as exposições eram iniciadas com a disposição das bancadas ou mesas de apoio em locais de grande circulação dos alunos - sem que estas prejudicassem o fluxo de pessoas, mas que, efetivamente, atraísse a atenção do público. Essas bancadas ou mesas recebiam forração em tecido claro, de modo a realçar os espécimes taxidermizados que seriam sobrepostos.

Segundo Auricchio e Salomão (2002), a taxidermia é uma técnica de manutenção da epiderme (pele) de vertebrados, sob tratamento químico. A taxidermia artística visa a exposição dos animais, isolados ou em dioramas, que simulam seu habitat, tendo foco educativo ou de entretenimento. A taxidermia científica tem como foco a salvaguarda de exemplares e a pesquisa.

Os espécimes taxidermizados são animais pertencentes à Mata Atlântica, bioma onde se encontra o Campus Orleans. Esse acervo científico é confeccionado por meio de uma oficina extraclasse envolvendo acadêmicos de Engenharia Ambiental e Sanitária e Medicina Veterinária do Unibave. Para a exposição nas escolas, os representantes desta coleção faunística foram: Caiman latirostris (jacarédo-papo-amarelo), Leopardus tigrinus (gato-do-mato-pequeno), Caretta caretta (tartaruga-marinha), Spheniscus magellanicus (pinguim-de-magalhães) e Arctocephalus australis (lobo-marinho-sul-americano), como indicado na Figura 1.

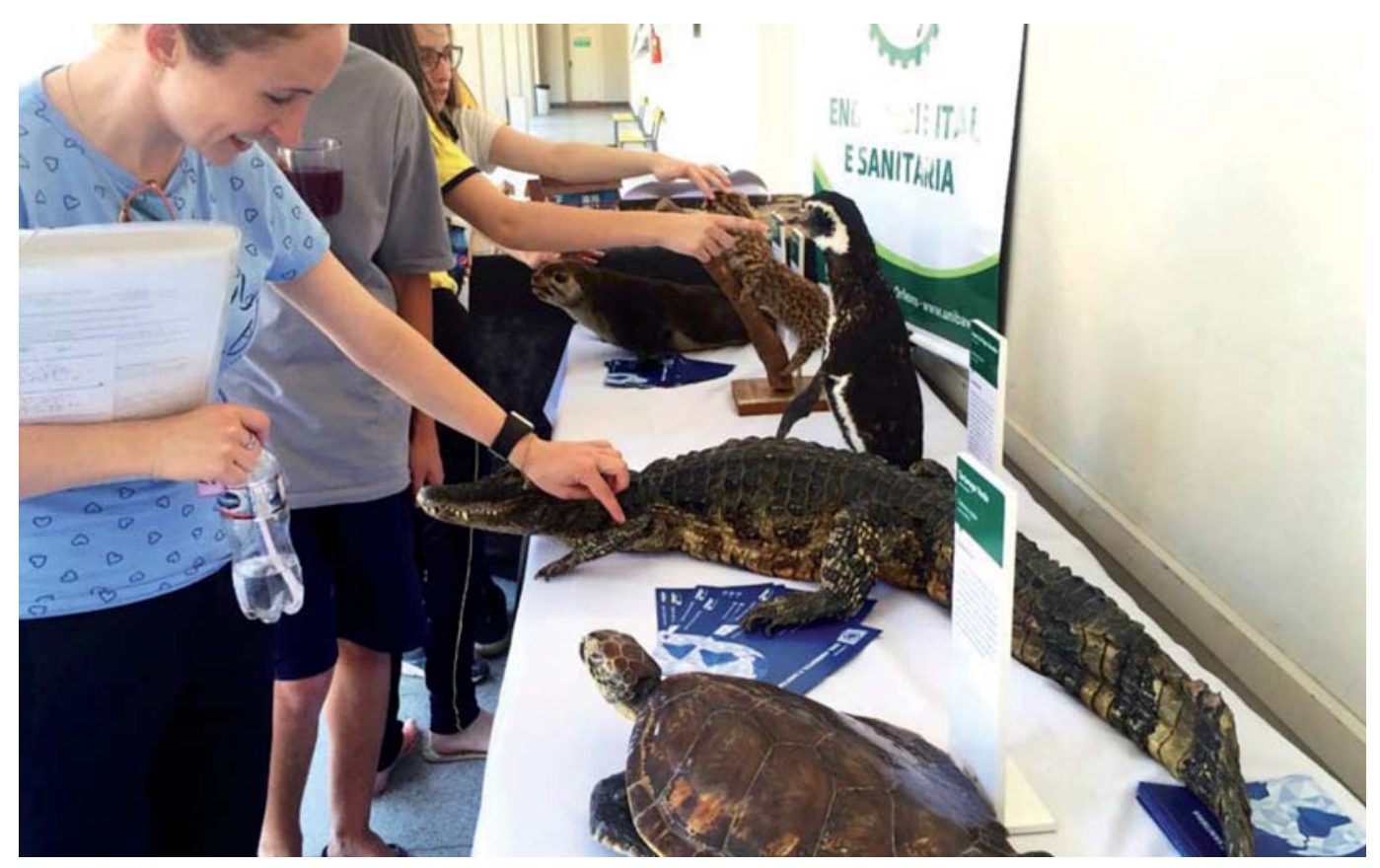

Figura 1 - acervo taxidermizado exposto na Escola de Educação Básica Barão do Rio Branco. Fonte: Ismael Dagostin Gomes, 2016.

Geralmente, as exposições permaneciam 02 dias inteiros em cada escola, organizadas no primeiro turno de funcionamento e desmontadas no último turno de funcionamento das mesmas, procurando abranger os horários de entrada, recreio e saída da comunidade escolar.

\section{Resultados}

Em seus quatro meses de operação (setembro - dezembro, 2016), considerando o público-alvo do projeto (Figura 2), de acordo com os dados de matrícula repassados pelas 11 escolas atendidas, a 
exposição "Biodiversidade e Educação Ambiental" atingiu diretamente 2.758 alunos do Ensino Médio, que somados aos do Ensino Fundamental Anos Finais, totalizam 5.397 alunos em geral, conforme o Quadro 1:

Quadro 1 - Escolas, período e participantes das exposições de taxidermia da Mata Atlântica.

\begin{tabular}{llcrr}
\hline Município & Escola & Período & EM & EF II + EM \\
\hline Orleans & E. E. B. Samuel Sandrini & $25-26 / 9$ & 112 & 699 \\
& Escola Barriga Verde & $6-7 / 10$ & 38 & 127 \\
Lauro Müller & E. E. B. Toneza Cascaes & $24-25 / 10$ & 280 & 490 \\
São Ludgero & E. E. B. Walter Holthausen & $2-4 / 11$ & 350 & 350 \\
Braço do Norte & Colégio Evolução & $7-8 / 11$ & 83 & 342 \\
Rio Fortuna & E. E. B. São Ludgero & $9-10 / 11$ & 370 & 1.217 \\
Urussanga & E. E. B. Dom Joaquim & $18-19 / 11$ & 654 & 996 \\
& E. E. B. Nossa Sa. de Fátima & $22-23 / 11$ & 154 & 369 \\
Gravatal & E. E. B. Barão do Rio Branco & $24-25 / 11$ & 271 & 546 \\
Subtotal (Público-Alvo) - Total & E. E. B. Caetano Bez Batti & $28-29 / 11$ & 246 & 614 \\
\hline
\end{tabular}

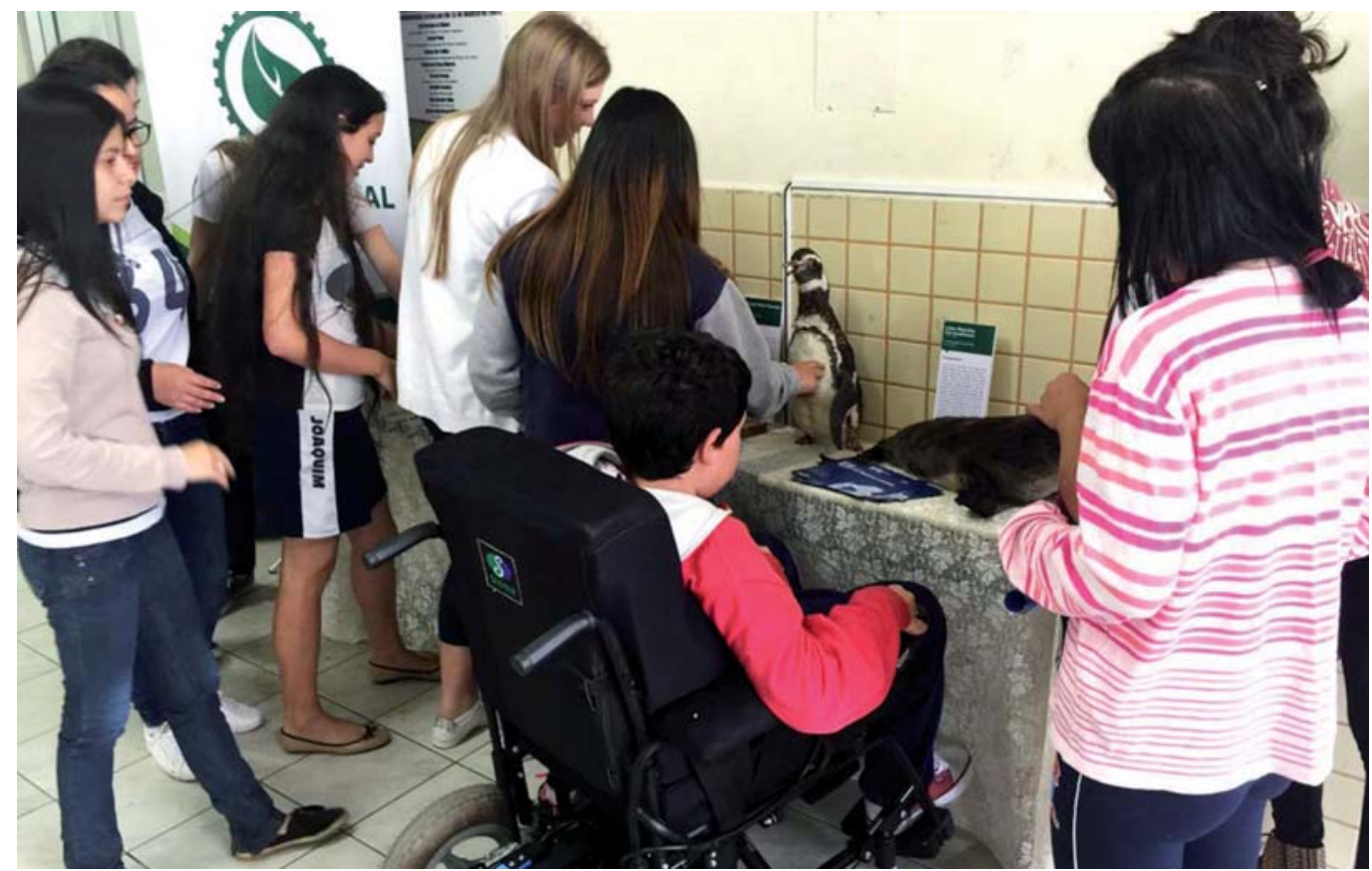

Figura 2 - alunos da Escola de Educação Básica Dom Joaquim visualizando a exposição. Fonte: Ismael Dagostin Gomes, 2016.

O projeto percorreu 07 municípios da área de abrangência do Unibave, situados na região das Encostas da Serra Geral: Orleans, Lauro Müller, São Ludgero, Braço do Norte, Rio Fortuna, Urussanga e Gravatal. O contingente populacional desses municípios, segundo a Associação dos Municípios da Região Carbonífera (AMREC, 2017) e a Associação de Municípios da Região de Laguna (AMUREL, 2017) é de 119.554 habitantes.

Ainda, a exposição atingiu alunos de outros níveis de ensino - como da Educação Infantil e dos Anos Iniciais do Ensino Fundamental, professores e funcionários das unidades escolares, além de pais e demais envolvidos no cotidiano dos estabelecimentos de ensino.

\section{Considerações Finais}

A realização das exposições, (tirar vírgula) possibilitou uma dinâmica diferenciada no cotidiano das escolas, já que despertou o interesse da comunidade escolar, apresentando um elemento incomum e atraente para os olhares dos expectadores, pressuposto indispensável para o "querer aprender". Tal 
fato alicerça o objetivo pedagógico da exposição como recurso didático.

Além disso, a exposição caracterizou-se como uma ação de inclusão social, pois promoveu mediação pedagógica para alunos e/ou professores com deficiência visual. Estsa questão, inclusive, foi absolutamente realçada pelas escolas participantes.

Projeta-se, para as próximas edições, um acervo com maior interatividade com o público, já que esta característica pode promover uma aprendizagem mais significativa, pois a comunidade escolar não se limita à observação estática, mas participa, ativamente, da interpretação e apropriação do saber.

Também, almeja-se aumentar o período de exposição em cada escola, e iniciar o período itinerante naos escolas colégios no primeiro semestre de cada ano, e não exclusivamente nos meses finais, pois algumas escolas já apresentam calendário limitado para inserções externas.

Por fim, conclui-se que o projeto "Biodiversidade e Educação Ambiental" do curso de Engenharia Ambiental e Sanitária do Unibave cumpriu seu objetivo, permitindo conhecimentos biológicos e sensibilização ambiental, contribuindo com o desenvolvimento regional sustentável das Encostas da Serra Geral.

\section{Referências}

AMREC. Municípios associados. Disponível em: <http://www.amrec.com.br/index/municipios-associados/codMapaItem/42512>. Acesso em: 27 mar. 2017.

AMUREL. Municípios associados. Disponível em: <http://www.amurel.org.br/index/municipios-associados/codMapaItem/41796>. Acesso em: 27 mar. 2017.

AURICCHIO, P; SALOMÃO, M. da G. (Org.). Técnicas de coleta e preparação de vertebrados para fins científicos e didáticos. São Paulo: Arujá: Instituto Pau Brasil, 2002.

BRASIL. Ministério da Educação - Secretaria de Educação Fundamental. Parâmetros curriculares nacionais: temas transversais - meio ambiente. Brasília: MEC/SEF, 1997.

BRÜGGER, P. Educação ou adestramento ambiental? $3^{\mathrm{a}}$ ed. Chapecó: Argos; Florianópolis: Letras Contemporâneas, 2004.

CARVALHO, I. C. de M. Educação ambiental: a formação do sujeito ecológico. 2a ed. São Paulo: Cortez, 2006.

MARANDINO, M; MONACO, L. M; OLIVEIRA, A. D. de. Olhares sobre os diferentes contextos da biodiversidade: pesquisa, divulgação e educação. São Paulo: GEENF/FEUSP/INCTTOX, 2010.

MILLER, G. T. Ciência ambiental. 11ª ed. São Paulo: Thomson Learning, 2007.

PEDRINI, A. de G. (Org.). Educação ambiental: reflexões e práticas contemporâneas. Petrópolis: Vozes, 1997.

REIGOTA, M. O que é educação ambiental. 2a ed. São Paulo: Brasiliense, 2009.

UNIBAVE. Plano de Desenvolvimento Institucional - PDI, 2014-2018. Orleans: Febave, 2014.

Recebido para publicação em 30/3/2017 e aprovado em 21/8/2017. 